\title{
Homemade ashmeter: a low-cost, high-efficiency solution to improve tephra field-data collection for contemporary explosive eruptions
}

\author{
Benjamin Bernard
}

\begin{abstract}
Tephra fall is a major volcanic hazard and deposit characteristics are critical data used to quantify eruptive material. The homemade ashmeter is a device used to precisely measure thickness, area density, and bulk density of small ash deposits $(<20 \mathrm{~mm})$. This instrument provides both direct measurements in the field and sample collection for laboratory analysis. The primary purpose of this device is to collect fallout from small-volume and distal eruption clouds. The homemade ashmeter is composed of an outer container, a funnel, an inner gauge, and a filter cap, and permits sampling without major weathering effects. It is constructed using mostly recycled materials, thus is very cost effective. To test this system, seven instruments were installed during the January 14 - March 16, 2012 eruption of Tungurahua volcano, Ecuador. The ashmeter allows the measurement and sampling of small tephra falls that can be used to improve fallout hazard assessments.
\end{abstract}

Keywords: Ashmeter, Volcanology, Tephra, sampling, Thickness, Area density, Bulk density, Homemade, Tungurahua, Resolution calculations

\section{Introduction and background}

Recent volcanic eruptions such as 2008 Chaitén, Chile (Martin et al. 2009) and 2010 Eyjafjallajökull, Iceland (Ulfarsson and Unger 2011) have reminded us that ash fall is one of the most hazardous volcanic products due to its widespread distribution by winds, and can pose far-field impacts to society. In order to assess this hazard several characteristics of the tephra fallout must be measured in the field. The traditional method for fallout data collection during a volcanic eruption follows the recommendations of the International Volcanic Health Hazard Network (2012). The thickness is the most frequently used parameter and is measured directly with a tape ruler on a flat area, preferably not affected by rain or wind (Walker 1973). This measurement is repeated several times at the same location to calculate average thickness (generally in $\mathrm{cm}$ or $\mathrm{mm}$ ) and then repeated in different locations to study the spatial distribution of the tephra fallout. Isopach maps created with these data are used to identify the origin of an eruption (vent), when

Correspondence: bbernard@usfa.edu.ec

Universidad San Francisco de Quito, Diego de Robles y Vía Interoceánica, Quito, Ecuador not observed, and to calculate the total volume of tephra using various empirical laws (Pyle 1989; Fierstein and Nathenson 1992, Bonadonna et al. 1998, Bonadonna and Costa 2012). The total volume of tephra is the main parameter used to estimate the Volcanic Explosivity Index (VEI) of an eruption (Newhall and Self 1982). The area density (mass-per-unit area, also called load) of tephra fallout is calculated principally for modern deposits just after the eruption. The area density is obtained by sampling a representative area (generally a square of $>20 \mathrm{~cm}$-side), drying the sample in the laboratory, and weighing the dry sample (Bonadonna et al. 1998; Scollo et al. 2007). The area density (generally given in $\mathrm{kg} / \mathrm{m}^{2}$ or $\mathrm{g} / \mathrm{m}^{2}$ ) is then calculated by dividing the weight of the sample by the sampling area. Isomass maps created with these data are used to calculate the total mass of tephra with the same methods as for isopach maps. The total mass of the eruptive products, including lava and pyroclastic flows, is used to calculate the Dense-Rock Equivalent (DRE) volume and the magnitude of the eruption (Tsuya 1955). The bulk density (generally given in $\mathrm{kg} / \mathrm{m}^{3}$ or $\mathrm{g} / \mathrm{cm}^{3}$ ) is calculated by dividing the area density by the thickness. This parameter, rarely used to its full potential, is critical 
to understanding the impact of tephra fallout on infrastructures and agriculture (Baxter 2000).

Although the methodology for field collection of tephra fall from ancient eruptions is not likely to change, new methods for sampling ash fall from modern eruptions is allowing for more precise collections (Bonadonna et al. 1998). According to the IVHHN, the most cost-effective technique for ash collection is using plastic trays (or buckets) installed around a volcano prior to the eruption. For example, since 2007, a group of volcanologists from the Instituto Geofísico de la Escuela Politécnica Nacional de Quito (2012) has installed about 30 ash-collection receptacles around Tungurahua volcano to improve volume estimations of frequent, small-scale tephra emissions (Bustillos and Mothes 2010). More recently, the use of a portable electronic scale with a $0.1 \mathrm{~g}$ resolution combined with the receptacles has permitted in situ measurement of area densities of less than $100 \mathrm{~g} / \mathrm{m}^{2}$ (Bernard et al. in preparation; Figure 1). Nevertheless, the methods used to measure or calculate the tephra deposit characteristics described above show several flaws: 1) heavy rains and strong winds

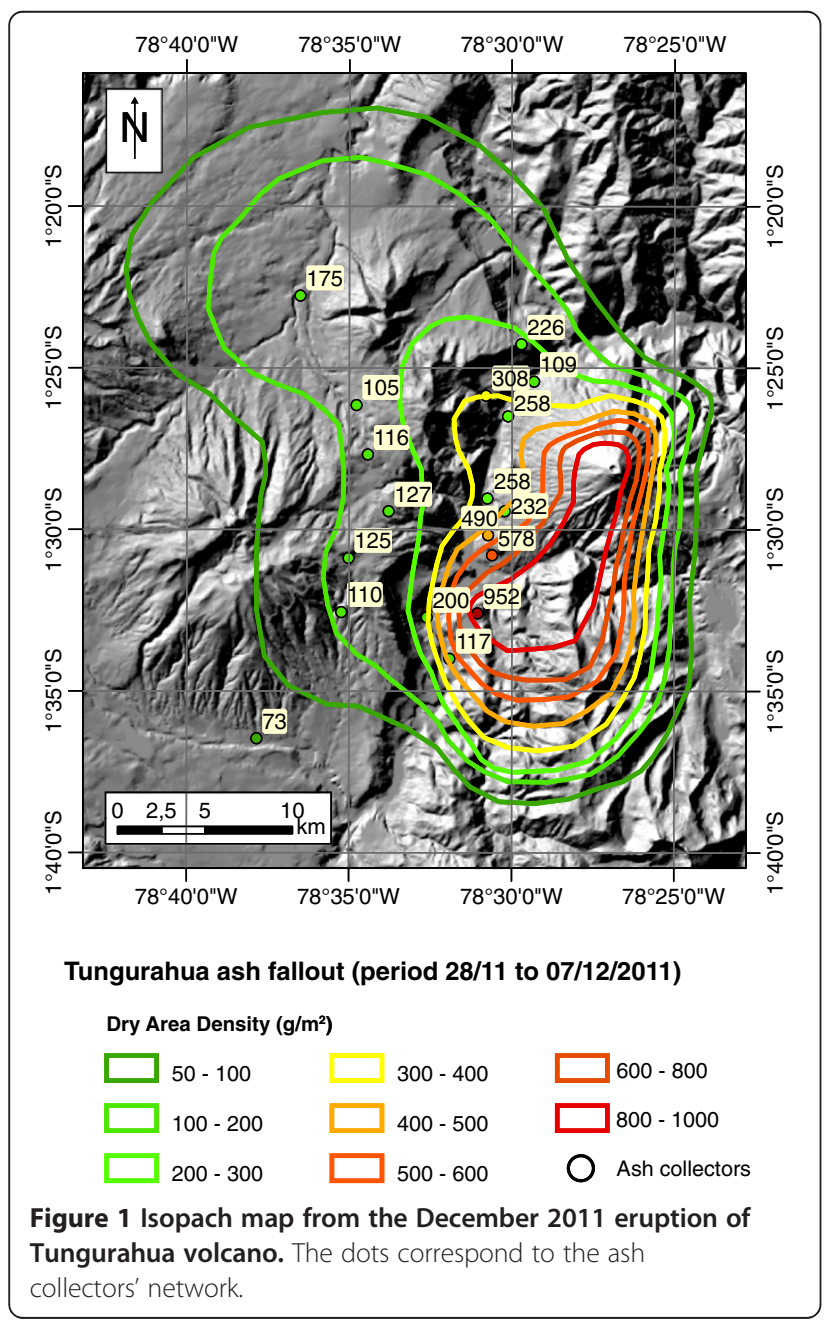

can drastically rework the deposit; 2) for deposits less than $1 \mathrm{~cm}$-thick, thickness measurements tend to be spurious and sampling is more difficult (Eychenne et al. 2012); and 3) when using trays, accumulation of pre-eruptive rain will impede some analyses, like leachates. This leads to small sample numbers and low-quality data, especially for small explosive eruptions and thin distal fallout from large-scale events, compromising tephra fall volume calculations (Bonadonna et al. 1998) and the understanding of volcanic ash transport (Riley et al. 2003). Precise fallout data are needed to feed and validate tephra dispersal and fallout models in order to produce realistic ash fall hazard maps (Carey and Sparks 1986; Bonadonna et al. 2005; Folch et al. 2008).

This paper presents a homemade device constructed using mostly recycled materials that collects thin ash falls while avoiding most impacts from weathering processes. Very precise layer thickness, area density, and bulk density are measured or calculated using the ashmeter. This work complies with a new guideline that encourages harmonization of tephra field-data collection so that tephra dispersal and fallout models can be improved and comparable among models (Bonadonna et al. 2011).

\section{How to construct an ashmeter}

The 10-minute video shown in Additional file 1 is a visual illustration of the step-by-step instructions presented in the following sections on how to build an ashmeter.

\section{Material requirements}

The following list contains the common materials required to construct an ashmeter (Figure 2): 1) A large plastic bottle with a cylindrical lower part and a conical upper part (slope $\geq 35^{\circ}$ ), used to construct the outer container and the funnel; 2) a small plastic bottle and its cap, used to construct the inner gauge and the filter cap; the diameter of the lower part of the small bottle must be larger than the large bottle neck; 3) large aperture (> $2 \mathrm{~mm}$ ) flexible plastic screen, used to protect the inner gauge from insects but allowing the volcanic ash to pass through; 4$)$ small aperture $(<2 \mathrm{~mm})$ rigid plastic screen, used to construct the filter cap; 5) paper filter (e.g. coffee filter or resistant kitchen paper), used to let the water pass through but not the fine-grained ash; 6) flexible wire, used to fix the funnel to the outer container; 7) hot silicone (e.g hot glue stick for craft making), used to glue the large aperture flexible plastic screen to the funnel; 8) permanent marker, used to calibrate the inner gauge; 9) transparent acetate paper or sticker for printer, used to print the inner gauge scale; 10) transparent adhesive tape, used to fix the inner 


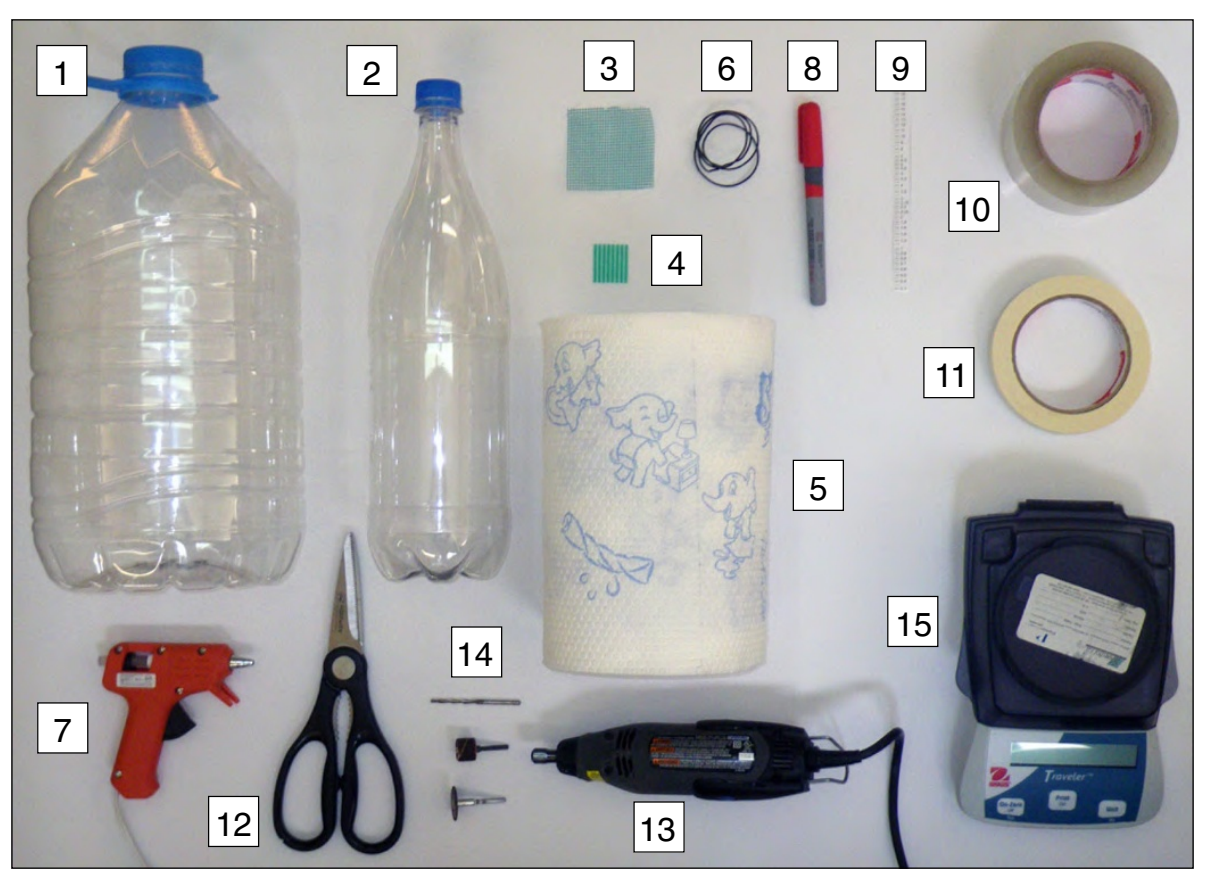

Figure 2 Material requirements to construct an ashmeter. 1) Large plastic bottle; 2) small plastic bottle; 3) large aperture (>2 mm) flexible plastic screen; 4) small aperture ( $<2 \mathrm{~mm}$ ) rigid plastic screen; 5) paper filter (resistant kitchen paper); 6) flexible wire; 7 ) hot silicone glue gun; 8) permanent marker; 9) inner gauge scale on transparent acetate sticker; 10) transparent adhesive tape; 11) masking tape; 12) scissors; 13) small handheld rotary tool with 14) accessories (circular saw and drill); 15) electronic scale.

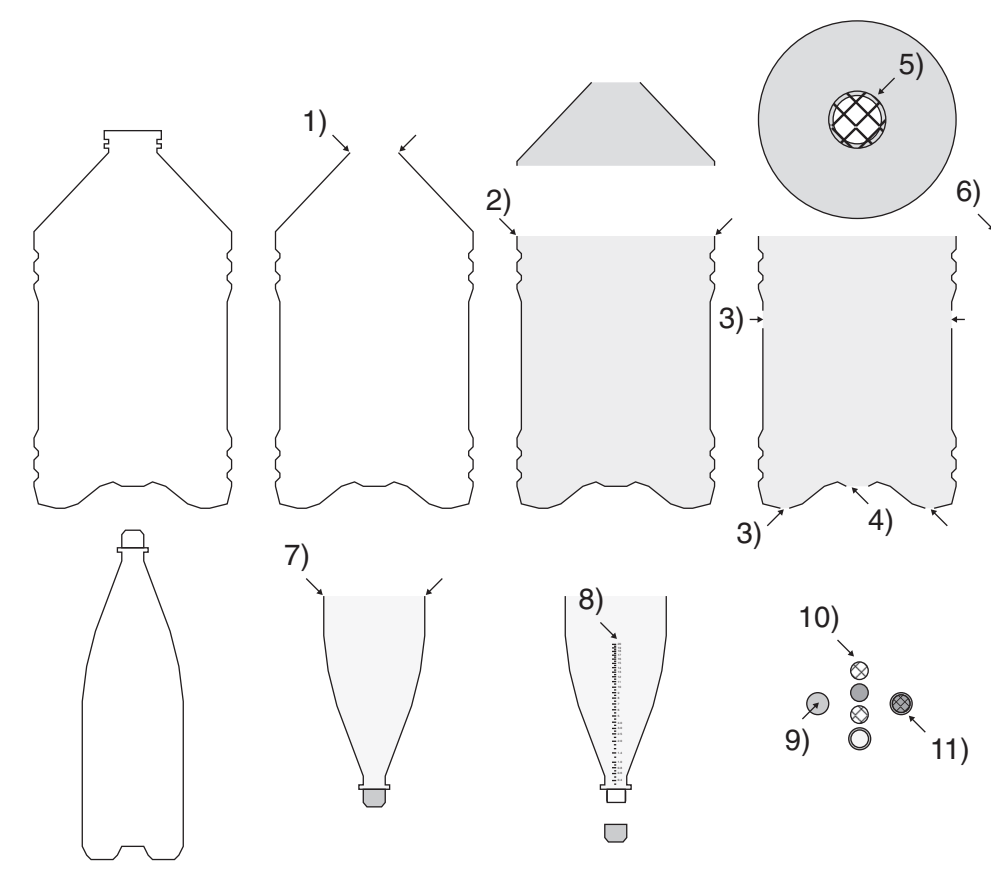

Figure 3 Steps to build the ashmeter. The arrows indicate where to achieve the actions described in the paragraph 1.2. 1) Remove the neck of the large bottle; 2) Remove the upper part of the large bottle; 3) Drill or cut holes in the lower part; 4) Drill a circular hole in the center of the lower part's base; 5) Glue a large aperture flexible screen to the smaller aperture of the large bottle's upper part; 6) Fix the funnel to the outer container; 7) Remove the bottom of the small bottle; 8) Create a thickness scale; 9) Drill a large hole in the cap of the small bottle; 10) Cut two plastic screens and a paper filter to fit in the cap; 11) Enclose the paper filter between the two plastic screens; 12) Assemble the different parts. 
gauge scale; 11) masking tape, used to mark the bottles for straight cuts.

Most of the material comes from recycling. The rest can be easily found in any hardware store. In addition, the construction of the ashmeter requires some tools like a hot glue gun, scissors, a small handheld rotary tool with accessories (circular saw and drill), and an electronic scale. The design and production of the inner gauge scale requires a computer with drawing software, a scanner, and a printer.

\section{Steps to build the ashmeter}

1) Remove the neck of the large bottle (Figure 3).

2) Remove the upper part of the large bottle about 5$10 \mathrm{~mm}$ below the break in slope. For a straight cut, mark the bottle with masking tape.

3) Drill or cut small holes in the lower part (top and bottom) to release humidity.

4) Drill a circular hole in the center of the lower of the large bottle, large enough so that the small bottle cap can pass through but small enough so that the whole neck of the small bottle won't be able to. The lower portion of the large bottle becomes the outer container (Figure 4).

5) Glue a large aperture ( $>2 \mathrm{~mm}$ ) flexible screen to the smaller aperture in the upper part of the large bottle. The upper portion of the large bottle becomes the funnel (Figure 4).

6) Turn the funnel upside-down and fix it to the outer container by threading small pieces of flexible wire in several places around the perimeter of the container.

7) Remove the bottom of the small bottle so the upper part, placed upside-down, will fit in the outer container and so the funnel will exert some pressure to keep it vertical. This becomes the sample collector.

8) Create a thickness scale on the sample collector through the following: a) calculate the area (A) of accumulation based on the radius $(r)$ of the outer container $\left(\mathrm{A}=\pi \mathrm{r}^{2}\right)$; b) create a chart calculating the volumes $(\mathrm{V})$ of water (density $\sim 1 \mathrm{~g} / \mathrm{cm}^{3}$ ) corresponding to different theoretical thicknesses (T) $(\mathrm{V}=\mathrm{AT})$. As the sample collector does not have a regular shape, graduation must be adapted to the bottle models; c) for each thickness, pour a volume equivalent of water in the sample collector and label the water level; d) test the graduation and calculate the real error on the measurement, given by the difference between the reading of the water thickness and the water weight; e) if the error is lower than the resolutions of the graduation (half graduation), it can be transferred to masking tape, scanned, and transformed into a computer-designed ruler sticker that will be printed on a transparent acetate sticker; f) fix the ruler sticker on the sample collector; g) test the graduation; h) protect the ruler sticker from humidity with transparent adhesive tape. This becomes the inner gauge (Figure 4). It is better to create two (or more) inner gauges for one ashmeter to ease the field sampling. Once the ruler
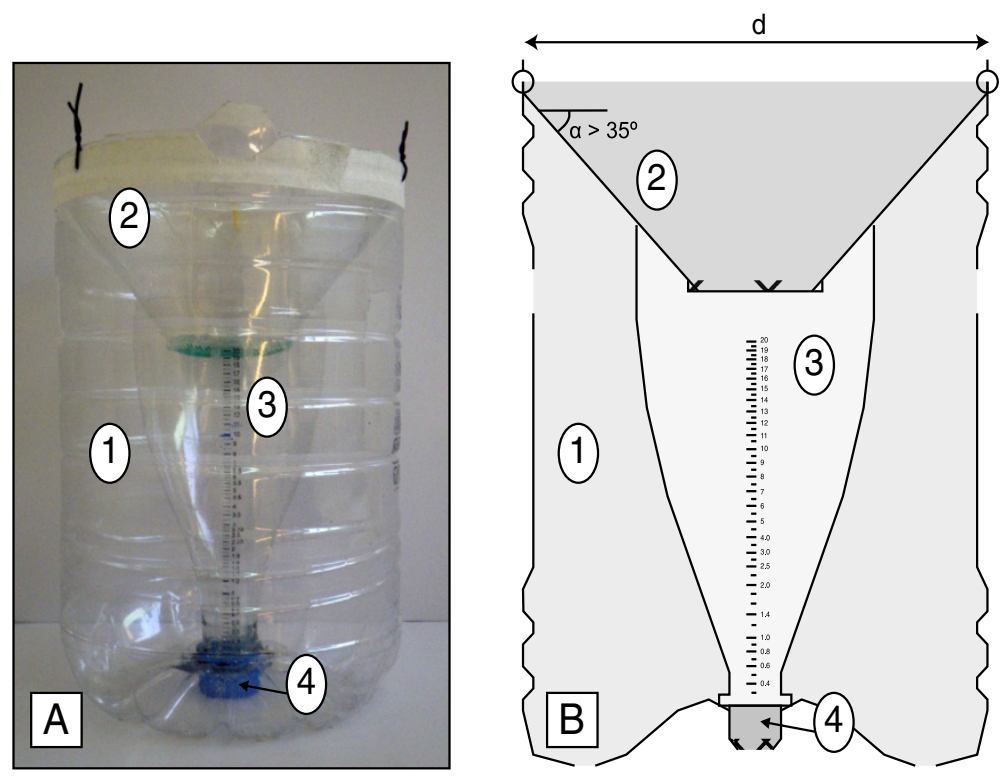

Figure 4 A) Photograph and B) Sketch of the ashmeter. 1) Outer container; 2) funnel; 3) inner gauge; 4) cap filter. Note the slope of the funnel $\left(>35^{\circ}\right)$ and the relationship between the size of the small bottle and the funnel lower aperture. 
sticker is created the steps a) to e) are not needed anymore. The resolution of the inner gauge, presented in details in the Additional file 2, depends on the number of graduations obtained during this process. The distance between two graduations should be at least $2 \mathrm{~mm}$ to insure a good reading.

9) Drill a large hole in the cap of the small bottle.

10) Cut two plastic screens and a paper filter to fit into the cap.

11) Place the paper filter between the two plastic screens and fix them to the interior of the cap. One plastic screen protects the paper filter from the ash fall and rain. The other is used to prevent the paper filter from falling from the cap. This becomes the filter cap (Figure 4).

12) Assemble the different parts. The ashmeter is ready to be installed.

\section{Time, cost, and installation}

With adequate tools, an ashmeter can be built in less than one hour. The most time-consuming task is calibrating the inner gauge. This step is greatly shortened once the ruler sticker is created. The cost of an ashmeter can be as little as one US dollar based on the use of recycled construction materials. The ashmeter must be installed vertically and fixed to a fence or a post in an open area without trees to avoid shadow effects or secondary accumulation (Figure 5A).

\section{Functionality of the ashmeter Measurements}

The ashmeter allows measurement or calculation of at least five parameters (see Table 1 and Additional file 2 for equations). Tephra thickness $(\mathrm{T})$ is read directly off the inner gauge (Figure 5B). Four measurements made with the inner gauge scale and a mobile scale ensure a more precise and representative value of the thickness. In addition to dry area density $\left(\rho_{\mathrm{A}(\mathrm{D})}\right)$, commonly used to create isomass maps (Scollo et al. 2007), the ashmeter allows calculation of in situ area density $\left(\rho_{\mathrm{A}(\mathrm{is})}\right)$ that can be particularly useful to assess fallout impact. Both parameters are calculated by dividing the mass of the tephra sample (measured in the field or dry in the laboratory) by the accumulation area (A). In situ $\left(\rho_{\mathrm{B}(\mathrm{is})}\right)$ and dry $\left(\rho_{\mathrm{B}(\mathrm{D})}\right)$ bulk densities of the deposit, also useful for tephra impact assessment, are obtained by dividing the area densities by the tephra thickness.

\section{Measurements resolution}

The three measurements used to calculate the different parameters of the fallout are thickness, accumulation area, and tephra mass. The errors in these three measurements have an impact on the results and must be carefully estimated. Use of the ashmeter, if constructed and calibrated as suggested here, will give high quality results (Figure 6A).

The range of thickness readings for the ashmeter presented in this paper (6-liter large bottle model and a 1.5liter small bottle model) is between 0.3 and $20 \mathrm{~mm}$. The

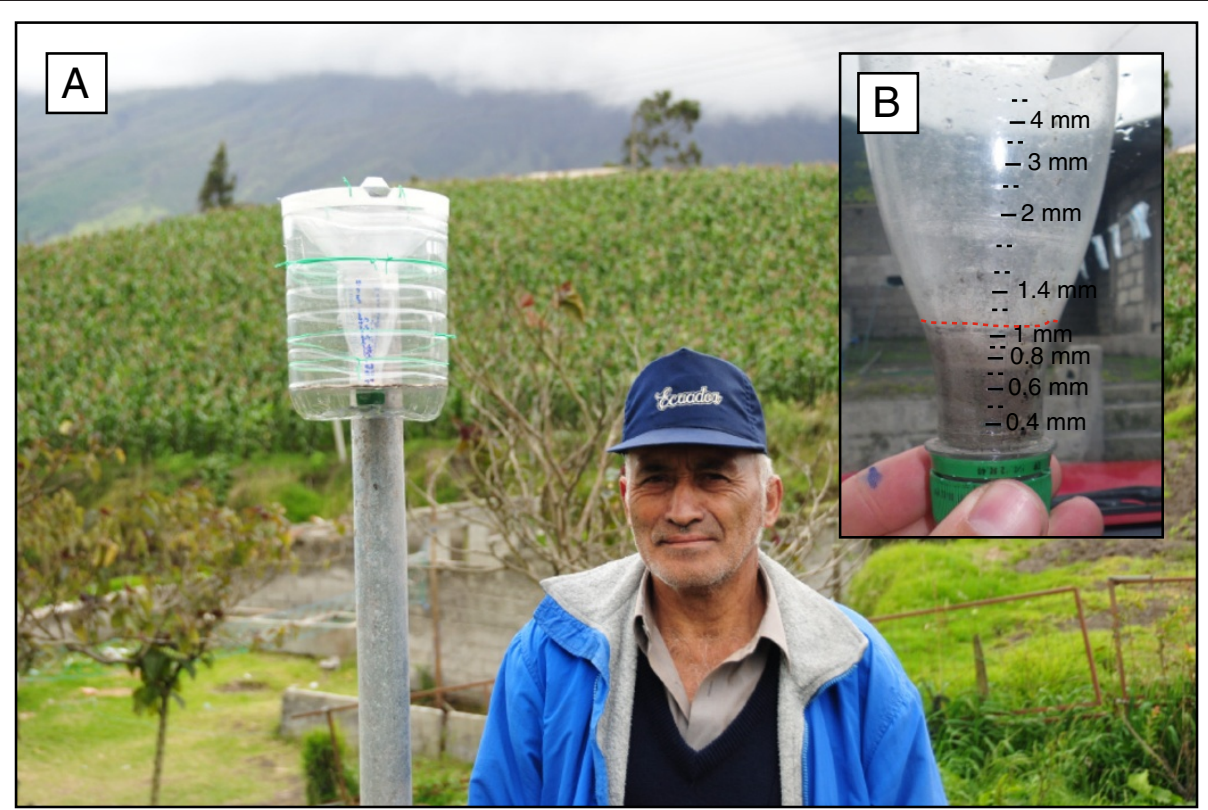

Figure 5 Installation of an ashmeter and sampling. A) Example of an ashmeter deployed in the backyard of Rodrigo Ruiz on January 14,2012 (Pillate); B) An example of a thin (1.1 mm-thick) deposit collected March 14, 2012 in Pillate, from the February 4, 2012 eruption. 
Table 1 First data collected with the ashmeter network at Tungurahua volcano (from January 14 to March 16, 2012)

\begin{tabular}{|c|c|c|c|c|c|c|c|c|c|}
\hline & Location & & CAH & $\mathrm{CHO}$ & JUI & OVT & PAL & PIL & RUN \\
\hline \multirow[t]{3}{*}{ Thickness } & Reading (mm) & $T$ & 0,65 & 1 & $<0,3$ & $<0,3$ & $<0,3$ & 1,1 & $<0,3$ \\
\hline & Absolute resolution (mm) & $\mathrm{R}_{\mathrm{A}(\mathrm{T})}$ & 0,05 & 0,05 & - & - & - & 0,1 & - \\
\hline & Relative resolution (\%) & $R_{R(T)}=R_{A(T)} / T$ & $7,7 \%$ & $5,0 \%$ & - & - & - & $9,1 \%$ & - \\
\hline \multirow[t]{3}{*}{ Ash weight (in situ) } & Value $(g)$ & $M 3=M 2-M 1$ & 17,5 & 34,2 & 4,0 & 0,8 & 1,8 & 35,6 & 7,6 \\
\hline & Absolute resolution (g) & $R_{A(M 3)}=\sqrt{ }\left(R_{A(M 1)}^{2}+R_{A(M 2)}^{2}\right)$ & 0,14 & 0,14 & 0,14 & 0,14 & 0,14 & 0,14 & 0,14 \\
\hline & Relative resolution (\%) & $R_{R(M 3)}=R_{A(M 3)} / M 3$ & $0,8 \%$ & $0,4 \%$ & $3,5 \%$ & $17,7 \%$ & $7,9 \%$ & $0,4 \%$ & $1,9 \%$ \\
\hline \multirow[t]{3}{*}{ Area density (in situ) } & Value $\left(\mathrm{g} / \mathrm{m}^{2}\right)$ & $\rho_{A(\text { is })}=M 3 / A$ & 818,4 & 1599,5 & 187,1 & 37,4 & 84,2 & 1665,0 & 355,4 \\
\hline & Absolute resolution $\left(\mathrm{g} / \mathrm{m}^{2}\right)$ & $R_{A(\rho A(i s))}=\rho_{A(i s)}{ }^{*} R_{R(\rho A(i s))}$ & 9,7 & 15,3 & 6,8 & 6,6 & 6,7 & 15,8 & 7,3 \\
\hline & Relative resolution (\%) & $R_{R(\rho A(i s))}=\sqrt{ }\left(R_{R(M 3)}^{2}+R_{R(A)}^{2}\right)$ & $1,2 \%$ & $1,0 \%$ & $3,6 \%$ & $17,7 \%$ & $7,9 \%$ & $0,9 \%$ & $2,0 \%$ \\
\hline \multirow[t]{3}{*}{ Bulk density (in situ) } & Value $\left(\mathrm{kg} / \mathrm{m}^{3}\right)$ & $\rho_{\mathrm{B}(\mathrm{is})}=\rho_{\mathrm{A}(\mathrm{is})} / \mathrm{T}$ & 1259,1 & 1599,5 & - & - & - & 1513,6 & - \\
\hline & Absolute resolution $\left(\mathrm{kg} / \mathrm{m}^{3}\right)$ & $R_{A(\rho B(i s))}=\rho_{B(i s)} * R_{R(\rho B(i s))}$ & 98,0 & 81,4 & - & - & - & 138,3 & - \\
\hline & Relative resolution (\%) & $R_{R(\rho B(i \mathrm{i}))}=\sqrt{ }\left(R_{R(\rho A(i \mathrm{~s})}^{2}+R_{R(\mathrm{~T})}^{2}\right)$ & $7,8 \%$ & $5,1 \%$ & - & - & - & $9,1 \%$ & - \\
\hline \multirow[t]{3}{*}{ Ash weight (dry) } & Value $(g)$ & $\mathrm{M} 6=\mathrm{M} 5-\mathrm{M} 4$ & 16,5 & 27,7 & 3,3 & 0,7 & 0,5 & 34,1 & 5,8 \\
\hline & Absolute resolution (g) & $R_{A(M 6)}=\sqrt{ }\left(R_{A(M 4)}^{2}+R_{A(M 5)}^{2}\right)$ & 0,14 & 0,14 & 0,14 & 0,14 & 0,14 & 0,14 & 0,14 \\
\hline & Relative resolution (\%) & $R_{R(M 6)}=R_{A(M 6)} / M 6$ & $0,9 \%$ & $0,5 \%$ & $4,3 \%$ & $20,2 \%$ & $28,3 \%$ & $0,4 \%$ & $2,4 \%$ \\
\hline \multirow[t]{3}{*}{ Area density (dry) } & Value $\left(\mathrm{g} / \mathrm{m}^{2}\right)$ & $\rho_{A(D)}=M 6 / A$ & 771,7 & 1295,5 & 154,3 & 32,7 & 23,4 & 1594,8 & 271,3 \\
\hline & Absolute resolution $\left(\mathrm{g} / \mathrm{m}^{2}\right)$ & $R_{A(\rho A(D))}=\rho_{A(D)}{ }^{*} R_{R(\rho A(D))}$ & 9,4 & 13,0 & 6,7 & 6,6 & 6,6 & 15,2 & 7,0 \\
\hline & Relative resolution (\%) & $R_{R(\rho A(D))}=\sqrt{ }\left(R_{R(M G)}^{2}+R_{R(A)}^{2}\right)$ & $1,2 \%$ & $1,0 \%$ & $4,4 \%$ & $20,2 \%$ & $28,3 \%$ & $1,0 \%$ & $2,6 \%$ \\
\hline \multirow[t]{3}{*}{ Bulk density (dry) } & Value $\left(\mathrm{kg} / \mathrm{m}^{3}\right)$ & $\rho_{\mathrm{B}(\mathrm{D})}=\rho_{\mathrm{A}(\mathrm{D})} / \mathrm{T}$ & 1187,2 & 1295,5 & - & - & - & 1449,8 & - \\
\hline & Absolute resolution $\left(\mathrm{kg} / \mathrm{m}^{3}\right)$ & $R_{A(\rho B(D))}=\rho_{B(D)}{ }^{*} R_{R(\rho B(D))}$ & 93,5 & 67,2 & - & - & - & 133,2 & - \\
\hline & Relative resolution (\%) & $R_{R(\rho B(D))}=\sqrt{ }\left(R_{R(\rho A(D)}^{2}+R_{R(T)}^{2}\right)$ & $7,9 \%$ & $5,2 \%$ & - & - & - & $9,2 \%$ & - \\
\hline
\end{tabular}

First data collected with the ashmeter network at Tungurahua volcano (From January 14 to March 16, 2012). CAH: Cahuají; CHO: Choglontus; JUI: Juive Grande; OVT: Observatorio del Volcán Tungurahua; PAL: Palitahua; PIL: Pillate; RUN: Runtun; A: Accumulation area; T: Thickness reading; M1: mass of inner gauge; M2: mass of inner gauge + in situ tephra load; $M 3$ : mass of in situ tephra; $M 4$ : mass of the receptacle used in laboratory; $M 5$ : mass of the receptacle + dry tephra load; M6: mass of dry tephra; $\rho_{\mathrm{A}(\mathrm{is})}$ : In situ area density; $\rho_{A(D)}$ : Dry area density; $\rho_{B(i s)}$ : In situ bulk density; $\rho_{B(D)}$ : Dry bulk density; $R_{A}$ : Absolute resolution; $R_{R}$ : Relative resolution. The ashmeters installed at this time (first generation) had a range of $0.3-10 \mathrm{~mm}$ and a resolution for thickness readings twice lower than the current model (fifth generation) used for the resolution calculation presented in the Additional file 2.

resolution of the thickness readings is not constant because of the shape of the inner gauge. For thin deposits, between 0.3 and $1 \mathrm{~mm}$, the ashmeter has a theoretical absolute resolution of $0.025 \mathrm{~mm}$ (half graduation), while for thicker deposits, between 7 and $20 \mathrm{~mm}$, this value is $0.25 \mathrm{~mm}$. If compared to a tape ruler with a constant theoretical absolute resolution of $0.5 \mathrm{~mm}$, the ashmeter allows thickness readings 2 to 20 times more precise than the traditional method (Additional file 2). To ensure the quality of the thickness reading a series of test with water has been carried out on four random inner gauges to look at the difference between the theoretical resolution and the real error (Figure 6B). From 64 thickness readings, only 9 measurements have a real error exceeding the theoretical resolution of the instrument. With the exception of one measurement, none of the real errors exceeded the theoretical resolution by more than 1 percent.

The accumulation area for the ashmeter presented in this paper is about $214 \mathrm{~cm}^{2}(\mathrm{r}=8.25 \mathrm{~cm})$. The resolution calculation gives a maximum error value of about 1 percent for this parameter.
The resolution of the final parameter, tephra mass, depends on the electronic scale used for the measurements. In the resolution calculation we used a portable electronic scale (ideal for field work) with a $0.1 \mathrm{~g}$ resolution. The error on the mass measurement rapidly decreases with an increase of the sample size.

Consequently, resolution errors of the area density and the bulk density for a $1 \mathrm{~mm}$-thick tephra deposit are respectively 1 and 5 percent, a value rarely obtained with the traditional method. The ashmeter system magnifies the ash thickness in the inner gauge in order to have better readings of thin tephra deposits. As most of the error in bulk density comes from errors in thickness readings, this error decreases when the size-ratio (diameter) between the outer container and the inner gauge increases so the magnification is greater. Nevertheless, compaction due to loading may contribute to a variable error in thickness readings and cannot be avoided. Therefore, thickness and bulk density data obtained with the ashmeter should be put in perspective and future experiments must be designed to assess this matter. 


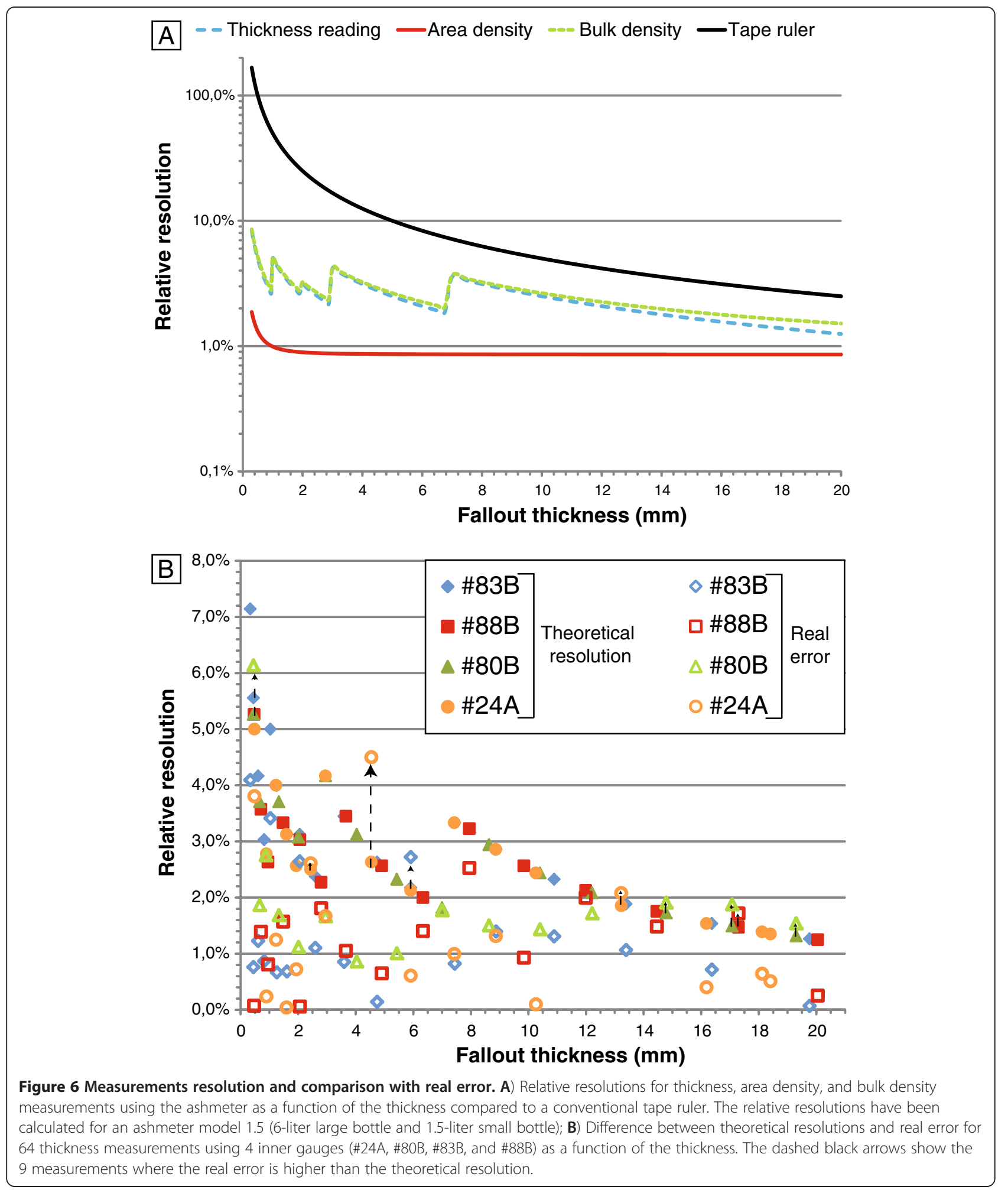

\section{Sampling tephra deposits}

One of the major advantages of the ashmeter is that it is designed to collect small, pristine (undisturbed) tephra samples that can be used to characterize very small eruptions through grain size, composition, shape, and textural analysis (Riley et al. 2003). The ashmeter design (shape of the inner gauge, the funnel, and the filter cap) prevents preeruptive rain accumulation in the inner gauge and posteruptive wind deflation process. Nevertheless to conserve pristine characteristics of the tephra deposit (bulk density, 
fine stratifications) it is important to collect the sample shortly after the ash fallout episode to avoid post-eruptive rain and fine-grained ash remobilization effects. The samples collected with the ashmeter are big enough for leachates analysis, laser diffraction grain-size analysis and SEM textural studies even for tephra fallout as thin as $1 \mathrm{~mm}$ (or about $20 \mathrm{~g}$ with the $8.25 \mathrm{~cm}$-radius outer container). Larger samples (e.g. for sieving) can be obtained by constructing the ashmeter using a larger outer container.

\section{First results from the $\mathbf{2 0 1 2}$ Tungurahua eruption}

On January 14 - 15, 2012, seven ashmeters were installed around Tungurahua volcano (Figure 7). The inner gauges of the ashmeters were collected on March 14 - 16, 2012. During this period the volcano produced three small ash emissions on February 4, February $22-25$, and March 3 - 7. According to the Tungurahua Volcano Observatory reports (http://www.igepn.edu.ec/index.php/ informes/volcanicos.html), the February 4 emission drifted westward in the direction of the Pillate station while the February 22 - 25, and March $3-7$ emissions drifted southwestward in the direction of the Choglontus and Cahuají stations. Nevertheless, all seven ashmeters collected some ash during this period. Characteristics of the samples are presented in Table 1 . Thickness readings were possible in 3 of the 7 ashmeters because the deposits were $\geq 0.3 \mathrm{~mm}$ thick (the threshold of the ashmeter); all others were too thin to record so only area density could be calculated for those stations. These results show a good relative resolution ( $<10$ percent) for the thickness readings and the bulk densities. The relative resolution for area densities vary between 1 and 28 percent for the seven samples, but only between 1 and 1.2 percent for the measurable samples (with thickness readings), highlighting the effect of the sample size on the resolution calculation.

There is a clear difference between the dry bulk densities in stations Pillate $\left(1450 \mathrm{~kg} / \mathrm{m}^{3}\right)$, Choglontus $\left(1296 \mathrm{~kg} / \mathrm{m}^{3}\right)$, and Cahuají $\left(1187 \mathrm{~kg} / \mathrm{m}^{3}\right)$. According to the Tungurahua Volcano Observatory, Pillate station was the most affected by the February 4 tephra fallout, whereas Choglontus and Cahuají stations accumulated principally during the February $22-25$ and March 3 7 eruptions. The difference of bulk density can be therefore associated to a difference in compaction time and rain effects but it could also be associated with the tephra characteristics (grain-size, composition). This highlights the importance of a rapid sampling after the fallout in order to avoid compaction associated with multiple overlapping deposits or rain effects. Since March 14, 40 more ashmeters have been deployed around Tungurahua volcano that will allow a better quantification of Tungurahua ash emissions (Bernard et al., in preparation).

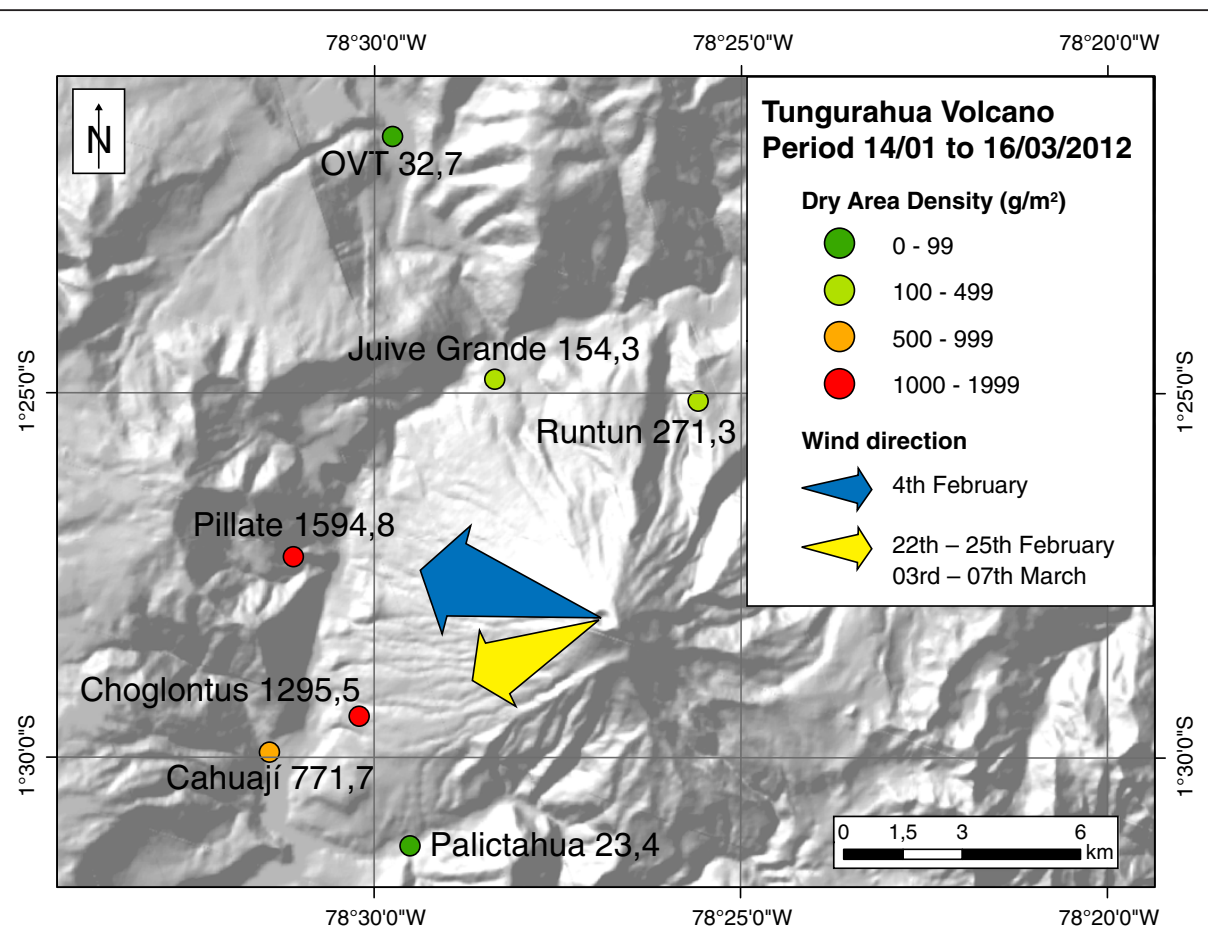

Figure 7 Map of Tungurahua volcano showing the ashmeter network. The dry area densities correspond to the ash collected within the first two months of installation (From January 14 to March 16, 2012). The arrows indicate the direction of the volcanic plume during the three small eruptions of February 4, February $22-25$, and March $3-7$, 2012. The size of the arrows indicates the relative size of the ash emissions. 


\section{Conclusion}

The homemade ashmeter is a low-cost device used to collect small-volume tephra falls and allows high-accuracy measurement or calculation of thickness, area density, and bulk density of tephra deposits without the influence of most weathering effects. The ashmeter permits improved tephra field-data collection at both a local and regional scale. A dense local network can be particularly useful in characterizing small, repetitive explosive eruptions such as the 2012 Tungurahua or Etna eruptions. A regional network could greatly help to quantify and study the impact of Plinian eruptions in distal areas, such as the 2011 Cordón Caulle eruption in Chile that produced small amounts of ash fallout in the coasts of Argentina, Uruguay, and Brazil. The first results from the 2012 Tungurahua eruption prove that ashmeters can provide high-quality measurements, even for extremely small volume or thin deposits. Since the ashmeters are easy to use, more rapid reporting of eruption parameters is possible and can be used in hazard assessments in near real time.

\section{Additional files}

Additional file 1: How to build the ashmeter (MP4). Video on how to build the ashmeter.

Additional file 2: Absolute and relative resolution calculation (DOC). Step by step calculation of the absolute and relative resolution of the ashmeter with full equations and comparison with the traditional tape ruler technique.

\section{Competing interest}

The author declares that he has no competing interests.

\begin{abstract}
Acknowledgements
This work is financially supported by the Universidad San Francisco de Quito. The author would like to thank the IGEPN, in particular S. Hidalgo and D. Andrade, J. Bustillos, A. Robles, J. Yuquilema, and D. Narváez for assistance with the development of the instrument, the installation of the network, and the collection of field-data. The author also would like to thank the personnel of OVT and the volunteers on Tungurahua volcano, whose observations during the eruption permit a better understanding of the data. The author acknowledges J. Quijozaca and B. Wade for their help in the construction of many ashmeters, installation, and collection of field-data. Stimulating discussions with P. Samaniego and JL Le Pennec (Institut de Recherche pour le Developpement, France) were much appreciated. B. Bartel and J. Lyons greatly helped to improve the understanding and the writing of the text. Two anonymous reviewers are acknowledged for their constructive and thorough reviews.
\end{abstract}

Received: 2 July 2012 Accepted: 20 December 2012 Published: 9 January 2013

\section{References}

Baxter PJ (2000) Impacts of eruptions on human health. In: Siggurdson H (ed) Encyclopaedia of Volcanoes. Academic, New York, pp 1035-1043

Bernard B, Wade B, Hidalgo S, Quijozaca J (in preparation) Quantification of Tungurahua tephra deposits for the eruptive period 2011-2012, Ecuador

Bonadonna C, Costa A (2012) Estimating the volume of tephra deposits: A new simple strategy. Geology 40-5:415-418. doi:10.1130/G32769.1

Bonadonna C, Ernst GGJ, Sparks RSJ (1998) Thickness variations and volume estimates of tephra fall deposits: the importance of particle Reynolds number. J Volcanol Geotherm Res 81:173-187
Bonadonna C, Scollo S, Cioni R, Pioli L, Pistolesi M (2001) Determination of the largest clasts of tephra deposits for the characterization of explosive volcanic eruptions: report of the IAVCEI Commission on Tephra Hazard Modelling. https://vhub.org/resources/870

Bonadonna C, Connor C, Houghton B, Connor L, Byrne M, Laing A, Hincks T (2005) Probabilistic modeling of tephra dispersal: hazard assessment of a multiphase rhyolitic eruption at tarawera, New Zealand. J Geophys Res-Solid Earth 110:B03203. doi:10.1029/2003JB002896

Bustillos J, Mothes P (2010) Ash falls at Tungurahua volcano: implementation of systematic ash collection for quantifying accumulated volumes, Cities On Volcanoes abstract volume, Tenerife. Canary Island, Spain, May 31 - June 4 2010, 2.7-0-07

Carey S, Sparks RSJ (1986) Quantitative models of the fallout and dispersal of tephra from volcanic eruption columns. Bull Volcanol 48:109-125. doi:10.1007/BF01046546

Eychenne J, Pennec J, Troncoso L, Gouhier M, Nedelec J (2012) Causes and consequences of bimodal grain-size distribution of tephra fall deposited during the August 2006 Tungurahua eruption (Ecuador). Bull Volcanol 74-1:187-205. doi:10.1007/s00445-011-0517-5

Fierstein J, Nathenson M (1992) Another look at the calculation of fallout tephra volumes. Bull Volcanol 54:156-167

Folch A, Cavazzoni C, Costa A, Macedonio G (2008) An automatic procedure to forecast tephra fallout. J Volcanol Geotherm Res 177:767-777

IGEPN (2012) Informes semanales del volcán Tungurahua. Instituto Geofísico de la Escuela Politécnica Nacional. http://www.igepn.edu.ec/index.php/informes/ volcanicos.html. Last visited Jan 2013

IVHHN (2012) Guidelines, ash collection procedures. International Volcanic Health Hazard Network. http://www.ivhhn.org/uploads/en/ IVHHN_Ash_Collection_Procedures.pdf. Last visited Jan 2013

Martin R, Watt S, Pyle D, Mather T, Matthews N, Georg R, Day J, Fairhead T, Witt M, Quayle B (2009) Environmental effects of ashfall in Argentina from the 2008 Chaitén volcanic eruption. J Volcanol Geotherm Res 184-3-4:462-472. doi:10.1016/j.jvolgeores.2009.04.010

Newhall CG, Self S (1982) The volcanic explosivity index (VEI): an estimate of explosive magnitude for historical volcanism. J Geophys Res 87:1231-1238

Pyle M (1989) The thickness, volume and grainsize of tephra fall deposits. Bull Volcanol 51:1-15

Riley CM, Rose WI, Bluth G (2003) Quantitative shape measurements of distal volcanic ash. J Geophys Res. doi:10.1029/2001JB000818, 108-B10, 2504

Scollo S, Del Carlo P, Coltelli M (2007) Tephra fallout of 2001 Etna flank eruption: Analysis of the deposit and plume dispersion. J Volcanol Geotherm Res 160:147-164. doi:10.1016/j.jvolgeores.2006.09.007

Tsuya H (1955) Geological and petrological studies on Volcano Fuji (V): on the 1707 eruption of Volcano Fuji. Bull Earthq Res Institute 33:341-383

Ulfarsson G, Unger E (2011) Impacts and responses of Icelandic aviation to the 2010 eyjafjallajökull volcanic eruption. Transportation research record. J Trans Res Board 2214-1:144-151. doi:10.3141/2214-18

Walker GPL (1973) Explosive volcanic eruptions - a new classification scheme. Geol Rundsch 62:431-446

doi:10.1186/2191-5040-2-1

Cite this article as: Bernard: Homemade ashmeter: a low-cost, highefficiency solution to improve tephra field-data collection for contemporary explosive eruptions. Journal of Applied Volcanology 2013 $2: 1$

\section{Submit your manuscript to a SpringerOpen ${ }^{\circ}$ journal and benefit from:}

- Convenient online submission

- Rigorous peer review

- Immediate publication on acceptance

- Open access: articles freely available online

- High visibility within the field

- Retaining the copyright to your article

Submit your next manuscript at $>$ springeropen.com 